\title{
PROMOTING PSYCHOLOGICAL RESILIENCE: PRESCHOOL TEACHERS' PERSPECTIVES
}

\author{
Eleni Nikolaou ${ }^{1^{\star}}$, Vasileios Papavasileiou ${ }^{2}$, Nikos Andreadakis ${ }^{3}$, Agapitos Xanthis ${ }^{4}$ \\ Yota Xanthacou ${ }^{5}$, Maria Kaila \\ ${ }^{1}$ Assistant Professor, University of the Aegean, GREECE, enikolaou@aegean.gr \\ ${ }^{2}$ Associate Professor, University of the Aegean, GREECE, vpapavasileiou@rhodes.aegean.gr \\ ${ }^{3}$ Associate Professor, University of the Aegean, GREECE, andread@rhodes.aegean.gr \\ ${ }^{4}$ Post-doc Researcher, University of the Aegean, GREECE, a.xanthis@rhodes.aegean.gr \\ ${ }^{5}$ Professor, University of the Aegean, GREECE, xanthakou@rhodes.aegean.gr \\ ${ }^{6}$ Professor, University of the Aegean, GREECE, kaila@rhodes.aegean.gr \\ ${ }^{*}$ Corresponding Author
}

\begin{abstract}
The present paper aims to explore preschool teachers' perspectives on the protective factors of preschool children's psychological resilience. The sample consisted of 156 preschool teachers. The data collection method was a questionnaire which was based on the theoretical background of psychological resilience. In particular, the perspectives of preschool teachers on the intra-individual, family and school factors that are considered resilience-enhancing were explored. The analysis of the research data shows that the teachers of the sample consider that parents' involvement in the development of children, parents' emotion understanding skills, communication within family and support from family members are among the main family factors that contribute to the development of psychological resilience of preschool children. As far as the intra-individual protective factors are concerned, problem solving skills, self-esteem and decisiveness are regarded as the most significant. Teacher support, school safety and positive relationships within the peer group are among the school factors that are considered that can serve as protective factors for promoting psychological resilience of preschool children. The extent to which teachers regard that psychological resilience is a stable characteristic has an effect on their perceptions about the significance of the protective factors. The above findings can contribute to the design and development of psychological resilienceenhancing programs.
\end{abstract}

Keywords: psychological resilience, teachers, preschool, perspectives

\section{INTRODUCTION}

Psychological resilience as a concept is defined as a characteristic, a process, a result, a pattern, a life course or a broad conceptual framework that includes all of the above. Definitions of resilience have changed with a shift to systemic thinking. Events such as climate change, natural disasters, war and pandemic have led to this conceptual shift (Masten, 2018). The review of the definitions and conceptual frameworks for resilience reveals the following definitions (Schultze-Lutter, Schimmelmann, \& Schmidt, 2016): the process of overcoming difficulties, adverse conditions or trauma for becoming more functional than before, the process of adapting to new or difficult situations, the process of recovery after difficult periods or trauma, psychological immunity with good mental health as well as personal strengths based on positive experiences and support.

Masten \& Cicchetti (2016) summarized the key issues of the systemic conceptual framework in the following 
principles: They argue that many interactive systems at multiple levels shape the operation and development of human systems and that a system's ability to adapt and develop is dynamic (constantly changing). The systems are interdependent. Individuals are part of the family and the family in turn is part of other systems (community, culture). Interactions between individuals, families and the wider context affect all interacting systems, although some of them are more influential (for example, the influence of family on children). From a systemic point of view psychological resilience is not a single or fixed characteristic, as it is a product of dynamic interactions involving many processes between systems. The resilience of a system at one level depends on the resilience of the associated systems. The psychological resilience of a child or a family depends on multiple contexts and interacting systems including relations. Therefore, the child's resilience depends on other systems that interact with the individual, especially on those that directly support the individual's resilience, such as the family. Individuals develop and change in different ways throughout development which affects the ability of the individual or family to adapt to challenges (Masten, 2018).

According to Masten \& Barnes (2018) resilience is a characteristic of both individuals and families, the economy, ecosystems and organizations. According to this view, the individual's ability to adapt to challenges depends on his/her relationships with others and systems. Psychological resilience reflects the adaptive ability to meet the challenges of the present or the future that the individual will face in a given context, at a given time. Psychological resilience is not just a trait although individual differences in personality or cognitive skills contribute to adaptability. Supportive relationships play an important role as well. Resilience in a growing organism is complex and dynamic. It changes because the individual and the contexts are constantly changing as a result of the multiple interactions between the individuals and the contexts.

\subsection{Psychological Resilience and Protective Factors}

O 'Dougherty Wright, Masten, \& Narayan (2013) refer to the following characteristics of psychological resilience which are examples of protective factors: a) the characteristics of the child include temperament in infancy, problem-solving skills, the ability to establish and maintain positive relationships with peers and effective strategies for regulating emotions and behaviour, b) family characteristics that include a stable and supportive family environment, harmonious relationship between parents, warmth, parental supervision, close relationship with caregivers who show sensitivity and respond to their children's needs, positive relationships with siblings, supportive relationships with extended family members, parental involvement in children's education and positive self-image (self-confidence, high self-esteem), (c) school characteristics which are related to children's ability to develop and maintain relationships with peers as well as developing positive relationships with teachers and other adults, (d) community characteristics, such as neighbourhood safety, low levels of neighbourhood violence, access to recreation centres, effective schools, well-trained teachers, employment opportunities for parents and a good public health system.

Protective agents positively modify individual's response directly or indirectly to a risk situation in transitional phases of life towards adaptive outcomes. Protective mechanisms can promote adaptive processes or mitigate negative processes. They can further reduce the impact of risk, reduce negative reaction chains, develop and maintain self-efficacy, or enable new opportunities. Protective mechanisms are factors that under certain conditions are associated with protective functionality in adverse conditions. Although the factors themselves are related to psychological functionality, the way an individual interacts with the environment and interpretations of adversity is a process of resilience that produces adaptive results. Some mechanisms have a global adaptive value while others are related to specific situations (Graber, Pichon, \& Carabine, 2015).

\subsection{Psychological Resilience Promotion}

According to Hornor (2017), promoting resilience is a complex issue that involves both macro-level and micro-level interventions. Microsystem interventions provide the framework for programs aimed at the community, family and the individual. Macrosystem interventions focus on the level of economics and social policy with the aim of creating community environments, attitudes and behaviours that promote safety, health and support. Macrosystem interventions aim to strengthen the resilience of the entire population and focus on the primary prevention of adverse childhood experiences.

Population-level interventions will have the greatest impact on the community and the individual. Legislation and policies aimed at reducing inequalities, improving access to higher education and access to mental health services are examples of promoting resilience at the society level. Interventions can be at the level of society, community, family and individual. Micro-level interventions seek to improve culture, attitudes of the community, school environment, peer group and families with the aim of developing communication skills and the associated values, such as parenting courses and school-based anti- bullying programs. These 
interventions aim at children's relationships by strengthening relationships with parents, siblings and peers. Healthy relationships promote resilience (Nikolaou \& Markogiannakis, 2017).

The theoretical background of resilience suggests that strengthening protective factors contributes to mitigating the negative effects of risks and to overcoming adversity. Interventions for children have been developed based on the above reasoning. However, a strengths-based systemic approach focuses on children's strengths and needs within the care system in which they are integrated.

Teachers, parents, other family members and the staff of preschool education structures are involved in planning interventions so that the target of change is the whole system. Proponents of this approach emphasize the importance of educating and supporting staff and parents with the aim of modifying children's environment (classroom, preschool education structures, family environment). Simultaneously, they support children in learning effective reactions (Lamb-Parker, LeBuffe, Powell, \& Halpern, 2008. Chiou, Zissi, Xanthacou, \& Andreadakis, 2000. Chiou, Zissi, Xanthacou, \& Kaila, 2005a)

\section{METHODOLOGY}

The present study explores preschool teachers' perspectives on the psychological resilience of preschool children. In particular, it explores a range of variables regarding the psychological resilience of preschool children. This paper presents teachers perceptions regarding the factors that are associated with the development of psychological resilience and it is a part of a wider research.

The research sample of the present study is composed of 156 teachers to whom the printed questionnaire was distributed and who stated their willingness to complete the questionnaire. The design of the research tool was based on the theoretical background of psychological resilience. The research sample consists of 150 women (96,2\%) and 6 men (3,8\%). 26,0\% of the sample are from 46 to 55 years old, $2,6 \%$ are from 56 to 65 years old, while there was no teacher over 65 years old in the research sample. $74,0 \%$ of teachers were working in general education kindergartens, while $26,0 \%$ were teachers in special education schools. The majority of teachers, i.e. $69,9 \%$ of the sample stated that they are university graduates, $20,9 \%$ are holders of a postgraduate degree, while only $2,0 \%$ are holders of a PhD degree. The largest percentage of the sample $(37,7 \%)$ has previous service from 0 to 5 years. $21,9 \%$ of teachers answered that they have 6 to 12 years of service, $13,9 \%$ have 13 to 18 years of service, $14,6 \%$ from 19 to 25 years of service and the 9,9 $\%$ of the sample from 26 to 30 years. Only $2,0 \%$ of the teachers in the sample had more than 31 years of service.

\section{RESULTS}

The above question that is related to the extent to which the teachers of the sample consider that the following intra-individual factors can act protectively for the development of children's psychological resilience, was covered with a total of 7 statements. Table 1 contains the distributions of teachers' responses to each of the statements referring to the intra-individual factors that contribute to development of children's psychological resilience. The means as well as the standard deviations of the answers are included in the same table.

The following results are derived from the data in Table 1: a) All intra-individual factors can play a protective role in the development of children's psychological resilience to a very significant degree. The percentages collected by all the statements are to a large extent on the scale from "to a moderate extent" to "to a very great extent". b) Three statements obtained the highest mean of teachers' perceptions in the response category "to a very great extent" and these were "Problem Solving Skills (PSS)", concentrating a percentage of $57,1 \%$ "Self-Esteem (SE)" with a percentage of $52,6 \%$ and "Decisiveness (D)" with $34,6 \%$. The means that correspond to the three categories are: PSS mean $=4,51$, SE mean $=4.47$ and D mean $=4,23$.

c) As far as the statement concerning the "Ability to solve problems", the categories "To a very great extent" and "To a great extent" gather in total $96,2 \%$ of the answers of the teachers, with the category "To a very great extent" obtaining a percentage of $40,4 \%$. This is a clear position of the sample teachers for this statement, d) the statement regarding "Self-Esteem" also gathers the largest percentage of answers in the categories "To a very great extent" and "To a great extent", in total the percentage is the $95,6 \%$ of the sample, with the category "To a very extent" obtaining a percentage of $52,6 \%$.

e) The attitude of teachers to the statement concerning the "Decisiveness" of children represents the $89,1 \%$ of the sample, i.e. almost 9 out of 10 teachers, consider that decisiveness is "To a very great extent " to "To a great extent" a protective factor for the development of children's psychological resilience. 


\section{Table 1}

Means and standard deviations of teachers' responses regarding the intra-individual factors that are related to the development of psychological resilience

\begin{tabular}{|c|c|c|c|c|c|c|c|}
\hline \multirow[t]{2}{*}{$\begin{array}{l}\text { To what extent do you } \\
\text { believe that the following } \\
\text { intra-individual factors can } \\
\text { act as protective factors } \\
\text { for the development of } \\
\text { children's psychological } \\
\text { resilience: }\end{array}$} & 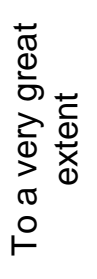 & 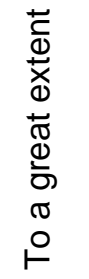 & 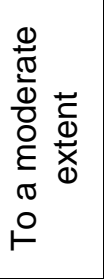 & 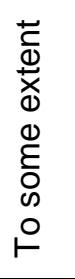 & $\begin{array}{l}\overline{\bar{\sigma}} \\
\bar{\sigma} \\
\overline{0} \\
\bar{Z}\end{array}$ & \multicolumn{2}{|c|}{ 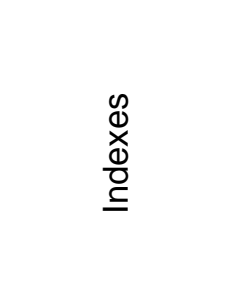 } \\
\hline & $\%$ & $\%$ & $\%$ & $\%$ & $\%$ & Mean & SD \\
\hline 1. Intelligence & 14,7 & 67,9 & 17,3 & 0,0 & 0,0 & 3,97 & 0,567 \\
\hline 2. Social Skills & 25,0 & 53,3 & 21,8 & 0,0 & 0,0 & 4,03 & 0,686 \\
\hline 3. Temperament & 21,8 & 51,3 & 23,1 & 3,8 & 0,0 & 3,91 & 0,774 \\
\hline 4. Self-esteem & 52,6 & 43,6 & 2,6 & 1,3 & 0,0 & 4,47 & 0,616 \\
\hline 5. Persistence & 29,5 & 55,8 & 14,1 & 0,6 & 0,0 & 4,14 & 0,667 \\
\hline 6. Decisiveness & 34,6 & 54,5 & 10,3 & 0,6 & 0,0 & 4,23 & 0,651 \\
\hline 7. Problem Solving Skills & 57,1 & 39,1 & 2,6 & 1,3 & 0,0 & 4,51 & 0,677 \\
\hline
\end{tabular}

$67,9 \%$ of the teachers consider that "Intelligence" can serve "to a great extent" as a protective factor, $14,7 \%$ of the sample of teachers believe that "Intelligence" is "to a very great extent" related to psychological resilience, and $17,3 \%$ of the sample consider that is related to "To a moderate extent". $51,3 \%$ of the sample consider that "Temperament" is related "to a great extent" to psychological resilience, $21,8 \%$ believe that it is related "To a very great extent", and $23,1 \%$ "to a moderate extent".

The next question, which concerned the extent to which, according to teachers' perspectives, a range of family factors can act as protectors for the development of children's psychological resilience, was explored with a total of 7 statements. Table 2 contains the distributions of teachers' responses to each of the statements referring to family factors for the development of children's psychological resilience. The averages as well as the standard deviations of the answers are included in the same table.

As shown in table 2: a) All statements are regarded as "Very Important" in relation to their protective function. In particular, according to teachers' responses, "Parents' involvement in the development of children" $(M=4,78)$ gathered the highest mean and "The existence of a support network in family life" $(M=$ 4,31 ) the lowest mean. b) None of the seven statements in the table received an answer in the category "Not at all". Thus, it seems that the teachers responded with certainty about the extent to which the statements in Table 2 are important.

c) As far as the statement regarding "Parents' involvement in children's development", 8/10 of the teachers in the sample agree that it can serve "to a very great extent" as a protective factor with a percentage of $79,5 \%$, the highest in this category. The statement with the lowest percentage in the same response category $(42,3 \%)$ pertains to the "existence of a support network in the life of the family".

d)The statement "Parents' ability to understand their children's feelings" gathered a percentage of $64,1 \%$ of teachers' responses in the category "To a very great extent" and a percentage of 35,9\% in the category "to a great extent". This statement is the only one of the seven statements in the table that did not receive any response in the other three categories "to a moderate extent", "to some extent" and "Not at all". In the same vein, the statement regarding "Parental involvement in child development" received only $1,3 \%$ of the responses in the category "to a moderate extent" as well as $0,0 \%$ and $0,0 \%$ in the other two lower categories of the five-point scale. 
e) The statement regarding "Setting limits on children's behavior" received on average more than half of the teachers' responses, i.e. $55,8 \%$ of the sample, in the category "To a very great extent", a percentage of "37,2\% in the category" to a great extent "and a percentage of $7,1 \%$ in the category" to a moderate extent". As far as this statement is concerned the mean $M=4,48$. $\mathrm{f}$ ) the "Existence of a support network in the life of the family" received a percentage of $42,3 \%$ teachers' responses in the category "To a very great extent", a percentage of $49,4 \%$ in the category "to a great extent", i.e. half of the teachers of the sample. $5,8 \%$ of the sample were located in the category "to a moderate extent" and $2,6 \%$ in the response category "to some extent".

\section{Table 2}

Means and standard deviations of teachers' responses regarding the family factors that are related to the development of psychological resilience

\begin{tabular}{|c|c|c|c|c|c|c|c|}
\hline $\begin{array}{l}\text { To what extent do you believe } \\
\text { that the following family factors } \\
\text { can serve as protective factors } \\
\text { in the development of } \\
\text { psychological resilience of } \\
\text { children? }\end{array}$ & 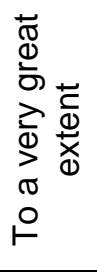 & 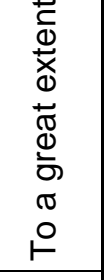 & 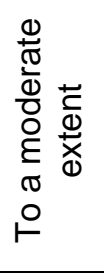 & 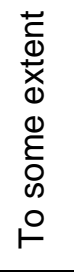 & 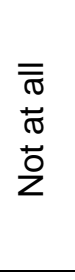 & \multicolumn{2}{|c|}{ 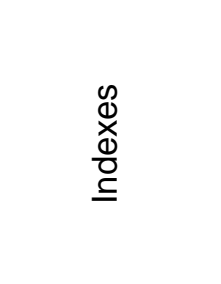 } \\
\hline & $\%$ & $\%$ & $\%$ & $\%$ & $\%$ & Mean & SD \\
\hline $\begin{array}{l}\text { 1. Communication within } \\
\text { the family }\end{array}$ & 63,5 & 34,0 & 2,6 & 0,0 & 0,0 & 4,61 & 0,540 \\
\hline $\begin{array}{l}\text { 2. Support from family } \\
\text { members }\end{array}$ & 66,7 & 25,6 & 7,7 & 0,0 & 0,0 & 4,59 & 0,631 \\
\hline $\begin{array}{l}\text { 3. Parents' ability to meet } \\
\text { their children's needs }\end{array}$ & 63,5 & 31,4 & 5,1 & 0,0 & 0,0 & 4,58 & 0,590 \\
\hline $\begin{array}{l}\text { 4. Parents' ability of } \\
\text { understanding their } \\
\text { children's emotions }\end{array}$ & 64,1 & 35,9 & 0,0 & 0,0 & 0,0 & 4,64 & 0,481 \\
\hline $\begin{array}{l}\text { 5. The existence of a } \\
\text { support network in } \\
\text { family life }\end{array}$ & 42,3 & 49,4 & 5,8 & 2,6 & 0,0 & 4,31 & 0,698 \\
\hline $\begin{array}{l}\text { 6. Setting limits on } \\
\text { children's behaviour }\end{array}$ & 55,8 & 37,2 & 7,1 & 0,0 & 0,0 & 4,49 & 0,627 \\
\hline $\begin{array}{l}\text { 7. Parents' involvement in } \\
\text { children's development }\end{array}$ & 79,5 & 19,2 & 1,3 & 0,0 & 0,0 & 4,78 & 0,444 \\
\hline
\end{tabular}

The next question which concerned the extent to which according to the teachers of the sample, a range of school factors can act as protectors for the development of children's psychological resilience, was explored with 6 statements in total. Table 3 contains the distributions of teachers' responses to each of the statements referring to the school factors that contribute to the promotion of children's psychological resilience. The means as well as the standard deviations of the answers are included in the same table.

The following results are derived from the data in Table 3: a) Four out of the six statements summarized teachers' perceptions of the sample as indicated the percentage of $100,0 \%$ in the three largest categories, i.e. "To a very great extent", "to a great extent" and "to a moderate extent", which demonstrates the clear position of teachers regarding the specific statements. While, the other two smaller categories "to a moderate extent" and "To some extent" did not gather any response from the teachers of the sample, as indicated the percentage of $0,0 \%$. b) In particular, regarding the statement "teachers' support to children", the perceptions of the teachers of the sample were gathered in the category "to a very great extent" $(57,1 \%)$, 
the category "to a great extent "received a percentage of 35,3\% (cumulatively equal to 92,4\%), the category" to a moderate extent", received $6,4 \%$ of the sample , while the category "to some extent" received only $1,3 \%$ of the sample responses. The mean of the indexes was $M=4,06$.

c) As far as the statement "Safety at school" is concerned, the statements of the teachers were gathered in the categories "To a very great extent" and "to a great extent" with a percentage of $49,5 \%$ and $47,5 \%$ respectively (cumulatively $97,0 \%$ ). The category "to a moderate extent" received a percentage of $3,0 \%$. The mean is $M=4,46$ for this statement. d) The "Cooperation of teachers with community services" is important according to the statements of the teachers of the sample as it gathers $86,8 \%$ of the answers. The category "to a moderate extent" follows with a percentage of $13,1 \%$. The mean is $M=4,47$ for the specific statement.

e) The "School climate" is, finally, "to a great extent " important according to the statements of the teachers indicated by the percentage of $60,3 \%$. The two largest categories in importance "To a very great extent" and "To a great extent" gathered $84,7 \%$ of the answers of the teachers of the sample. The response category "to some extent" received $2,6 \%$ of the responses. The mean is $M=4,06$ for this statement.

\section{Table 3}

Means and standard deviations of teachers' responses regarding the school factors that are related to the development of the psychological resilience

\begin{tabular}{|c|c|c|c|c|c|c|c|}
\hline $\begin{array}{l}\text { To what extent the above school } \\
\text { factors can serve as protective factors } \\
\text { for the development of psychological } \\
\text { resilience of children? }\end{array}$ & 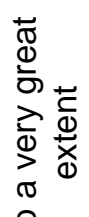 & 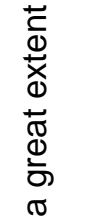 & 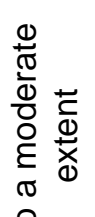 & 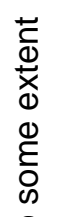 & $\begin{array}{l}\overline{\bar{\sigma}} \\
\bar{\sigma} \\
+ \\
\text { O }\end{array}$ & \multicolumn{2}{|c|}{ 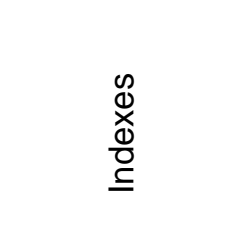 } \\
\hline & $\%$ & $\%$ & $\%$ & $\%$ & $\%$ & Mean & SD \\
\hline 1. School climate & 24,4 & 60,3 & 12,8 & 2,6 & 0,0 & 4,06 & 0,688 \\
\hline 2. Teachers' support & 57,1 & 35,3 & 6,4 & 1,3 & 0,0 & 4,48 & 0,677 \\
\hline $\begin{array}{l}\text { 3. Positive relationships with the } \\
\text { peer group }\end{array}$ & 48,7 & 42,3 & 9,0 & 0,0 & 0,0 & 4,40 & 0,649 \\
\hline $\begin{array}{l}\text { 4. Positive relationships with } \\
\text { teachers }\end{array}$ & 44,2 & 42,3 & 13,5 & 0,0 & 0,0 & 4,31 & 0,697 \\
\hline $\begin{array}{l}\text { 5. The cooperation between } \\
\text { school and community } \\
\text { services }\end{array}$ & 35,9 & 51,3 & 12,8 & 0,0 & 0,0 & 4,23 & 0,661 \\
\hline 6. School safety & 50,0 & 47,4 & 2,6 & 0,0 & 0,0 & 4,47 & 0,550 \\
\hline
\end{tabular}

One of the research questions of the present research was related to whether intra-individual factors can serve as protective factors for promoting preschool children's psychological resilience, based on the extent to which they consider psychological resilience to be a consistent characteristic of the child.

Table 4 shows that problem solving skills $(M=4,51, S D=0,677)$, self-esteem $(M=4,47, S D=0,616)$ and decisiveness $(M=4,23, S D=0,651)$ are considered the most significant protective factors according to preschool teachers' perceptions. Research data indicate that there were not statistically significant differences between the variables examined.

The extent to which teachers believe that psychological resilience is a stable characteristic has a significant effect on their perceptions about the significance of the following family factors: support from family members $(t=4,094, p=0,000)$, parents' meeting their children's needs $(t=2,703, p=0,008)$, parents' ability of understanding their children's emotions $(t=3,192, p=0,002)$ and the existence of a support network in family life $(t=2,357, t=0,020)$. The statistical data are presented in table 5 . In particular, the respondents that regard that psychological resilience is a stable characteristic to a low extent tend to believe that the above family 
characteristics are more important.

The extent to which teachers believe that psychological resilience is a stable characteristic has a significant effect on their perceptions about the significance of the protective factor "positive relationships with the peer group" ( $t=2,983, p=0,003)$ and the factor "positive relations with teachers" $(t=2,000, p=0,047)$. In particular, the respondents that regard that psychological resilience is a stable characteristic to a low extent tend to believe that the above school factors are more important (the statistical data are presented in table 6).

\section{Table 4}

Means and standard deviations of teachers' responses to whether the intra-individual factors that can act protectively to develop children's psychological resilience, based on the extent to which they consider psychological resilience to be a consistent characteristic of the child. Statistical significance test of the differences of the means

\begin{tabular}{|c|c|c|c|c|c|c|}
\hline \multirow{3}{*}{ Intra-individual factors } & \multicolumn{4}{|c|}{$\begin{array}{c}\text { Psychological Resilience } \\
\text { as a stable trait }\end{array}$} & \multicolumn{2}{|c|}{ Statistical Significance Test } \\
\hline & \multicolumn{2}{|c|}{ Low extent } & \multicolumn{2}{|c|}{ High Extent } & & \\
\hline & $M$ & s. d & $M$ & SD & $\mathrm{t}$ & $p$ \\
\hline Intelligence & 3,97 & 0,49 & 3,98 & 0,64 & $-0,150$ & $.988^{*}$ \\
\hline Social skills & 4,04 & 0,62 & 4,03 & 0,75 & 0,132 & $.895^{\star}$ \\
\hline Temperament & 3,99 & 0,68 & 3,84 & 0,85 & 1,214 & $.227^{*}$ \\
\hline Self-esteem & 4,53 & 0,58 & 4,43 & 0,65 & 1,026 & .306 \\
\hline Persistence & 4,17 & 0,62 & 4,11 & 0,71 & 0,547 & .585 \\
\hline Decisiveness & 4,24 & 0,67 & 4,23 & 0,64 & 0,113 & .910 \\
\hline Problem Solving Skills & 4,59 & 0,50 & 4,43 & 0,81 & 1,567 & $.120^{*}$ \\
\hline
\end{tabular}

${ }^{*}$ Corrected t, due to inequality of variances

\section{Table 5}

Means and standard deviations of teachers' responses to whether family factors that can act protectively to develop children's psychological resilience, based on the extent to which they consider psychological resilience to be a consistent characteristic of the child. Statistical significance test of the differences of the means.

\begin{tabular}{|c|c|c|c|c|c|c|}
\hline \multirow{3}{*}{ Family factors } & \multicolumn{4}{|c|}{ Psychological resilience as a stable trait } & \multirow{2}{*}{\multicolumn{2}{|c|}{ Statistical Significance Test }} \\
\hline & \multicolumn{2}{|c|}{ Low extent } & \multicolumn{2}{|c|}{ High extent } & & \\
\hline & M & s. d & M & s. d & $\mathrm{t}$ & $p$ \\
\hline Communication within family & 4,68 & 0,52 & 4,54 & 0,55 & 1,710 & $.089^{*}$ \\
\hline Support from family members & 4,79 & 0,41 & 4,40 & 0,74 & 4,094 & $.000^{*}$ \\
\hline Parents' meeting their children's needs & 4,71 & 0,46 & 4,46 & 0,67 & 2,703 & $.008^{*}$ \\
\hline
\end{tabular}


IJASOS- International E-Journal of Advances in Social Sciences, Vol. VII, Issue 19, April 2021

\begin{tabular}{|l||c|c||c|c||c|c||}
\hline $\begin{array}{l}\text { Parents' ability of understanding their } \\
\text { children's emotions }\end{array}$ & 4,76 & 0,43 & 4,53 & 0,50 & 3,192 & $.002^{*}$ \\
\hline $\begin{array}{l}\text { The existence of a support network in } \\
\text { family life }\end{array}$ & 4,45 & 0,62 & 4,19 & 0,75 & 2,357 & .020 \\
\hline Setting limits on children's behaviour & 4,54 & 0,58 & 4,44 & 0,67 & 1,015 & .312 \\
\hline $\begin{array}{l}\text { Parents' involvement in children's } \\
\text { development }\end{array}$ & 4,80 & 0,40 & 4,76 & 0,48 & 0,563 & .574 \\
\hline
\end{tabular}

${ }^{* *}$ Corrected $t$, due to inequality of variances

\section{Table 6}

Means and standard deviations of teachers' responses to whether school factors that can act protectively to develop children's psychological resilience, based on the extent to which they consider psychological resilience to be a consistent characteristic of the child. Statistical significance test of the differences of the means

\begin{tabular}{|c|c|c|c|c|c|c|}
\hline \multirow{3}{*}{ School factors } & \multicolumn{4}{|c|}{ Psychological resilience as a stable trait } & \multirow{2}{*}{\multicolumn{2}{|c|}{ Statistical significance Tes }} \\
\hline & \multicolumn{2}{|c|}{ Low extent } & \multicolumn{2}{|c|}{ High extent } & & \\
\hline & M & SD & M & SD & $\mathrm{t}$ & $\mathrm{p}$ \\
\hline School climate & 4,14 & 0,61 & 3,99 & 0,76 & 1,432 & .154 \\
\hline Teachers' support & 4,55 & 0,72 & 4,41 & 0,63 & 1,296 & .197 \\
\hline Positive relationships with the peer group & 4,55 & 0,58 & 4,25 & 0,68 & 2,983 & .003 \\
\hline Positive relations with teachers & 4,42 & 0,64 & 4,20 & 0,74 & 2,000 & .047 \\
\hline $\begin{array}{l}\text { The cooperation between school and } \\
\text { community services }\end{array}$ & 4,20 & 0,65 & 4,26 & 0,67 & $-0,614$ & .540 \\
\hline School Safety & 4,53 & 0,53 & 4,43 & 0,57 & 1,151 & .251 \\
\hline
\end{tabular}

${ }^{* *}$ Corrected $t$, due to inequality of variances

\section{CONCLUSIONS}

It appears that preschool teachers believe that problem solving skills, self-esteem and decisiveness can serve as important protective factors for promoting psychological resilience. In addition, preschool teachers suggest that parents' involvement in the development of children, communication within family, and the existence of support for family members are among the most important resilience-enhancing factors. Furthermore, school safety, positive relationships with the peer group and teacher support are regarded as significant protectors. The extent to which teachers regard that psychological resilience is a stable characteristic has an effect on their perceptions about the significance of the protective factors. These findings can be utilized in designing developmentally appropriate interventions taking into account educators' perceptions. Interventions should be tailored to the needs of preschool children. It is essential that assets and resources are developed at preschool age. The ultimate goal of designing interventions programs is to enhance protective factors at all levels of social ecology with the aim of enhancing the positive adaptation of children. 


\section{REFERENCE LIST}

Graber, R., Pichon, F., \& Carabine, E. (2015). Psychological resilience. London: Overseas Development Institute.

Hornor, G. (2017). Resilience. Journal of Pediatric Health Care, 31(3), 384-390.

Lamb-Parker, F., LeBuffe, P., Powell, G., \& Halpern, E. (2008). A strength-based, systemic mental health approach to support children's social and emotional development. Infants \& Young Children, 21(1), 4555.

Masten, A. S. (2018). Resilience theory and research on children and families: Past, present, and promise. Journal of Family Theory \& Review, 10(1), 12-31.

Masten, A. S., \& Cicchetti, D. (2016). Resilience in development: Progress and transformation. Developmental psychopathology, 1-63.

Masten, A. S., \& Barnes, A. J. (2018). Resilience in children: Developmental perspectives. Children, 5(7), 98.

Masten, A.S., \& O' Dougherty Wright, M. (2010). Resilience over the lifespan handbook of adult resilience. In J.W. Reich, A.J. Zautra \& J.S. Stuart Hall (Eds.), Handbook of adult resilience. USA: The Guildford Press.

Nikolaou, E., \& Markogiannakis, G. (2017). The role of teacher in primary school students' mental health promotion. Global Journal of Human-Social Science: Arts and humanities-Psychology, 17(5).

O' Dougherty Wright, M., Masten, A., \& Narayan, A. (2013). Resilience processes in development: Four waves of research on positive adaptation in the context of adversity. In S. Goldstein \& R.B. Brooks (eds.), Handbook of Resilience (pp.15-39). USA: Springer.

Papastylianou, A., Kaila, M., \& Polychronopoulos, M. (2009). Teachers' burn out, depression, role ambiguity and conflict. Social Psychology of Education, 12, 295-314.

Schultze-Lutter, F., Schimmelmann, B. G., \& Schmidt, S. J. (2016). Resilience, risk, mental health and wellbeing: associations and conceptual differences. European Child \& Adolescent Psychiatry, 25(5), 459466.

Chiou, B., Zissi, A., Xanthacou, Y., \& Andreadakis, N. (2000). Mental health and educational planning: Implementation of an intervention in Kindergarten (In Greek). In F. Kalavassis \& A. Kodakos (eds. pp. 282-297). Issues of Educational Planning (In Greek). Athens: Atrapos.

Chiou, V., Zissi, A., Xanthacou, Y., \& Kaila, M. (2005a). Mental health promotion: Intervention in preschool children. In A. Zissi, N. Polemikos, \& M. Kaila (Eds, pp. 124 - 149), Mental Health. Athens: Atrapos. 